\title{
The Development of the Employer Brand in the Labour Market
}

\author{
Aleksandra Marcikic Horvat \\ University of Novi Sad, Faculty of Economics in Subotica, Serbia \\ Radovan Pejanović \\ University of Novi Sad, Faculty of Agriculture, Serbia \\ Zoran Ćirić \\ University of Novi Sad, Faculty of Economics in Subotica, Serbia \\ Bojana Ćirić \\ University of Novi Sad, Faculty of Economics in Subotica, Serbia \\ Otilija Sedlak \\ University of Novi Sad, Faculty of Economics in Subotica, Serbia \\ Leposava Grubić - Nešić \\ University of Novi Sad, Faculty of Technical Sciences, Serbia
}

\section{Abstract}

Nowadays, the lack of high qualified staff is more conspicuous than ever before. The development of new knowledge and professions is followed by the modern technological changes, enormous usage of Internet and development of artificial intelligence. These trends have led to changes in the behaviour and access of both sides in the labour market. Candidates who have specific knowledge, skills and experience have the opportunity to choose the companies they want to work in, setting the conditions for employers. Companies, employers, who need some special skills are forced to make an effort to stand out and attract the attention of the target group. Therefore, the branding activities of the employer became crucial in a modern labour market. The aim of the paper is to identify the dimensions of attractiveness in branding employers and the levels of importance of each dimension. The results of the survey indicate that candidates are looking for many additional information about the employer. Each generation has certain ways and channels of gathering information that it considers credible. If employers do not recognize or ignore those channels, they miss the possibility of establishing and building relationships with candidates before employment itself.

Keywords: branding employers, labour market, marketing, human resources, economy

JEL classification: M31, M54, 015

\section{Introduction}

Engagement of an appropriate expert enables branding of almost everything: companies, people, touristic destinations, products, services etc. The main purpose of branding on the market is to make customers decide about acquisition much earlier than the actual exchange of products and services happens. Decision on purchase should be made in advance on the basis of positioning of products/product names/brands into customers mind. In this case, the result of acquisitions is already predetermined; branding sells products or services in advance. Branding contributes 
to simpler and much more efficient trade (Anselmsson, Bondesson and Johansson, 2014).

During 1990s a new category was defined: the "Employer branding", meaning the reputation of a company as an employer, compared to corporate reputation. Building of employer branding was in the focus of big international companies between 2004 and 2008 (Dell et al., 2001). At start, these activities were mainly externally oriented, i.e. towards new employees.

For brand is one of the most valuable ingredients of company's assets, brand management is part of the set of key activities of every company. Most of the companies usually develop their brands of products and services, but in the same time they also pay due attention to employer branding on labor market. "The employer brand is targeted, long-term strategy of managing awareness and perception of existing and new employees and other stakeholders (Sullivan, 2004; Backhaus and Tikoo, 2004)".

Employer brandig is applied by a company in order to present on the market its value as an employer (employer value proposition), so improving the process of regrutation of new work force, keeping existing employees and appreciating the value of the human capital (Backhaus and Tikoo, 2004).

Employer branding is an activity based on marketing principles, specifically on the "branding science", and is applied to activities in the area of human resources, aimed towards existing and potential employees (Edwards, 2009).

\section{Integrative framework of employer branding}

The conceptual frame serves as a tool for understanding employer branding; it is based on the concept of human resources and on the marketing concept.

Figure 1

Employer Branding, A Conceptual Frame

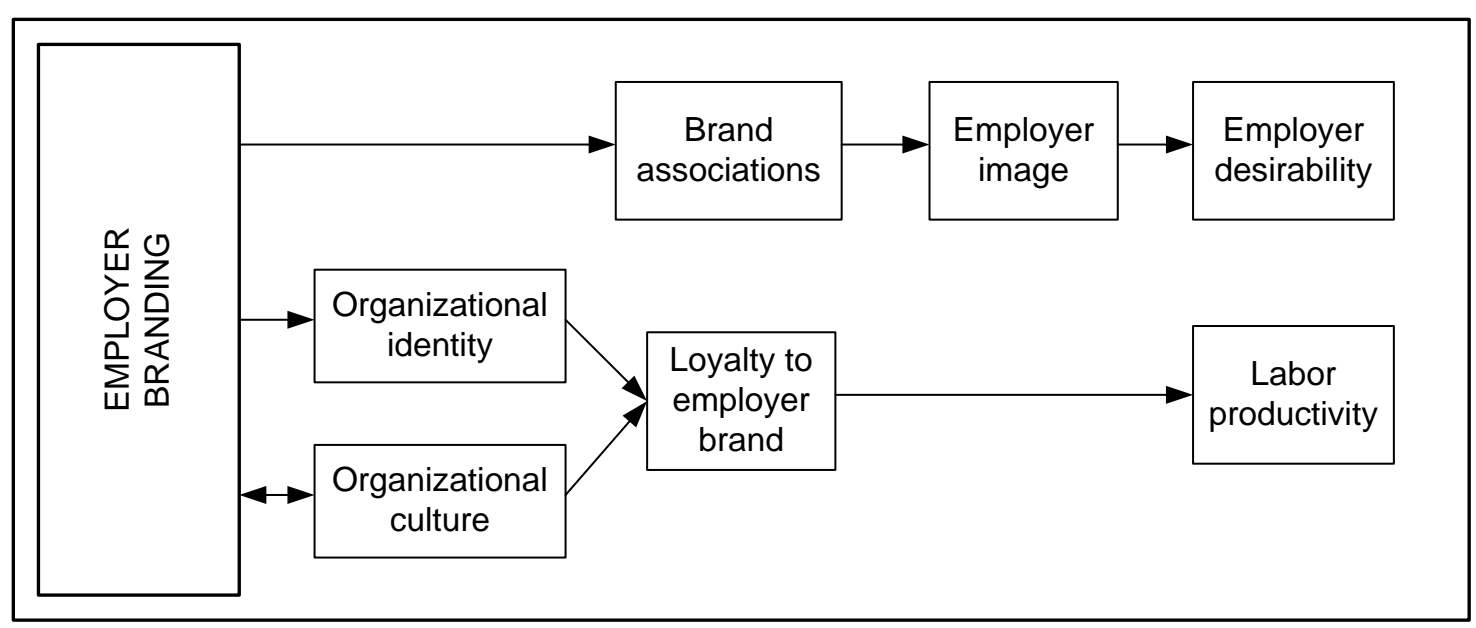

Source: Backhaus and Tikoo, 2004

Employer brand creates two basic elements: brand associations and brand loyalty. Brand associations form employer's image, and that influences the desirability of the company as an employer. Employer brand has effects onto organizational culture and identity, and that contributes to the loyalty to employer's brand, and so rises labour productivity. 


\section{Methodology}

We conducted an investigation on employer branding using a questionnaire titled: Development of employer brand on labour market. The main goal of our analyses was to identify dimension of attractiveness in employer branding, to determine the level of importance of every dimension, and to find statistically significant differences between respondents belonging to different genders or age groups and have various working positions (Pejanović et al., 2016). The investigation was performed through an on-line questionnaire on a random sample in the period from August to September, 2018. The questionnaire was formulated based on principles established by Collins \& Han and Chunping \& Xi (Collins and Han, 2004; Chunping and Xi, 2011).

The first part of the questionnaire included basic information on the respondents: gender, age group, educational level, working experience, workplace position, town of employment, area of working, years of service, current level of your workplace position, new plans on employment, acceptable type of employer.

The second part of the questionnaire consists of six questions related to information on job opportunities and factors that influence either retaining or changing workplace. For every question several alternatives are offered and the respondents would for some questions grade the possibilities with scores from 1 to 5 , and for others choose from offered possibilities or choose from answers yes or no.

Question 12: When searching for a new job, what is the grade of usefulness of the next channels to gain information about your chances: Google, websites for free jobs, official website of an employer, Facebook, personal contacts, press, and national employment office? (Please assign grades 1 to 5)

Question 13: When you find an advertisement for a job, do you ask for additional information on the employer? (YES or NO)

Question 14: To gain information on the employer how often do you use next sources: Google, Linkedln, Facebook, websites where current employees exchange their information, official website of the employer, websites for job ads, personal contacts, job fairs, National agency for business register? (Please assign grades 1 to 5)

Question 15: When looking after a job, what is the level of importance of the next factors: wage, job security, promotion possibilities, human relations, corporative culture, employer's reputation, flexible working hours, modern equipment and technology, private health insurance, use of business cars? (Please assign grades 1 to 5)

Question 16: What is the level of importance of the next factors to remain with the current employer: wage, permanent job, flexible working hours, human relations, promotion possibilities, recognition of results? (Please assign grades 1 to 5)

Question 17: What are the main reasons you would leave your current employer: impossibility of promotion, low wages, not precise position in working teams, results not recognized, human relations? (Please choose 1, 2 or 3 answers).

\section{Results}

On-line, we obtained a random sample of 136 valid questionnaires. Of all respondents 126 were employed $(113$ full-time employees, 5 part-time employees and 8 freelancers), 8 were students and only 2 of them were unemployed. There were 83 female and 53 male respondents. Around one half of respondents were younger than 30 years, and the average overall age was 31.6 years. The educational structure was the next: $19 \%$ of all respondents finished high school, $40 \%$ has higher education, $28 \%$ are BA, $12 \%$ are MSC and $1 \%$ finished doctoral studies. 
Since our investigation is related to jobs and years of service, we pay special attention to appropriate information on respondents. Related data are present in the next table.

Table 1

Years of Service

\begin{tabular}{lcccc}
\hline \multirow{2}{*}{ Years of service } & \multicolumn{2}{c}{ Total } & \multicolumn{2}{c}{ At current workplace } \\
\cline { 2 - 5 } & Frequency & Structure (\%) & Frequency & Structure (\%) \\
Less than 1 year & 17 & $12.5 \%$ & 34 & $25.0 \%$ \\
$\mathbf{1}-\mathbf{3}$ years & 27 & $19.9 \%$ & 46 & $33.8 \%$ \\
$\mathbf{3}-\mathbf{5}$ years & 25 & $18.4 \%$ & 13 & $9.6 \%$ \\
$\mathbf{5}-\mathbf{7}$ years & 14 & $10.3 \%$ & 43 & $31.6 \%$ \\
$\mathbf{7}-\mathbf{1 0}$ years & 14 & $10.3 \%$ & & \\
More than $\mathbf{1 0}$ years & 39 & $28.7 \%$ & & \\
\hline
\end{tabular}

Source: Authors' work

The half of the respondents has more than 5 years of service, and here is included the greatest part, who has more than 10 years of service. The average for respondents was $8.42( \pm 7.66)$ years of service in total and $4.98( \pm 4.87)$ years of service with the current employer. The majority of respondents (80) has been being employed for less than three years with the actual employer, 13 of them has between three and five years of service, and 43 respondents has been working more than 5 years. Three quarters of those who have more than 10 years of service in total has been working with the current employer for more than five years. A smaller number, i.e. $31 \%$ of employed persons intend to change their working places, around half them during the next 6 months and the rest during the next 12 months. The next table points to the fact that around $40 \%$ of workers do not have any preference about the type of ownership of the company they work for. In the case it is a privately-owned company, there is no reason to prefer either domestic or foreign owners.

Table 2

Type of Employers Preferred by Employees

\begin{tabular}{lrr}
\hline \multicolumn{1}{c}{ Type } & Frequency & Structure (\%) \\
\hline Privately owned company, domestic owners & 39 & $28.7 \%$ \\
Privately owned company, foreign owners & 37 & $27.2 \%$ \\
State owned company & 6 & $4.4 \%$ \\
Without preference & 54 & $39.7 \%$ \\
Total & 136 & $100.0 \%$ \\
\hline
\end{tabular}

Source: Authors' work

In the next table it is shown that when looking for a new workplace respondent most often use various websites where information is gathered about free jobs and job offers, and rank them as the most useful for them (grade 4.19). The next most important source is represented by personal contacts, which is followed by official websites of diverse employers. It is a bit disappointing fact that the grade for the National employment office is the lowest, while one could expect this is the most important information source for all unemployed and those who intend to find a new job. 
Table 3

Importance of Information Sources When Searching for New Jobs

\begin{tabular}{lrr}
\hline \multicolumn{1}{c}{ Information source } & Average grade & St. dev. \\
\hline Google & 3.32 & 1.34 \\
Websites for free jobs & 4.19 & 1.10 \\
\hline Official websites of employers & 3.74 & 1.27 \\
\hline Facebook & 2.86 & 1.29 \\
Personal contacts & 4.01 & 1.12 \\
Press & 1.83 & 1.07 \\
National employment office & 1.67 & 1.06 \\
\hline Total & 3.09 & 1.19 \\
\hline Source: Authors' work & &
\end{tabular}

Source: Authors' work

More than $95 \%$ of respondents stated that it is inevitable to gain various data on their future employer. Averages of using of different information sources about the employer are given in the next table (Table 4). Around three quarters of information employees gather from Google, and also from official websites of the employers. Similarly, personal contacts are frequent source information, followed by numerous websites for job ads, Facebook and Linkedln as well. Again, the main official source (the National agency for business register) is rarely used by employees.

Table 4

Sources of Information about the Employer

\begin{tabular}{lrc}
\hline \multicolumn{1}{c}{ Information source } & $\begin{array}{c}\text { Average usage } \\
\text { (\%) }\end{array}$ & $\begin{array}{c}\text { St. dev. } \\
\text { (\%) }\end{array}$ \\
\hline Google & 74.26 & 21.34 \\
\hline Linkedln profil of the employer & 59.12 & 27.53 \\
\hline Facebook of the employer & 60.29 & 26.01 \\
\hline Websites where employees exchange their opinions & 54.56 & 26.34 \\
\hline Official website of the employer & 73.24 & 21.86 \\
\hline Websites for job ads & 62.94 & 23.95 \\
\hline Personal contacts & 71.03 & 23.18 \\
\hline Job fairs & 25.00 & 21.66 \\
\hline National agency for business register & 35.59 & 28.25 \\
\hline Total & 57.34 & 24.58 \\
\hline
\end{tabular}

Source: Authors' work

Data in Table 5 refer to the importance of various factors for employees (Ciric, Stojic and Sedlak, 2015). These factors have an effect on their attitude towards the job they are currently engaged in, and influence their decision about accepting a specific job offer. It may require serious sociological and possibly psychological studies the fact that the most important issue was the item Human relations, which earned the highest grade. On the second place are wages, and mutually close are the importance of job security, promotion possibilities and corporative culture. To remain on a specific working place, it is highly important for workers that their workplace is stable (not temporary) and they expect their achievements to be fully recognized. 
Table 5

Importance of Factors Influencing Decision about a Working Place

\begin{tabular}{|c|c|c|c|c|}
\hline \multirow[t]{2}{*}{ Factors } & \multicolumn{2}{|c|}{$\begin{array}{l}\text { To accept a new } \\
\text { working place }\end{array}$} & \multicolumn{2}{|c|}{$\begin{array}{l}\text { To keep the current } \\
\text { working place }\end{array}$} \\
\hline & $\begin{array}{r}\text { Average } \\
\text { grade }\end{array}$ & St. dev. & $\begin{array}{r}\text { Average } \\
\text { grade }\end{array}$ & St. dev. \\
\hline Wage & 4.29 & 0.70 & 4.32 & 0.80 \\
\hline Job security & 4.05 & 0.97 & & \\
\hline Promotion possibilities & 4.04 & 0.91 & 3.98 & 0.95 \\
\hline Human relations & 4.43 & 0.84 & 4.46 & 0.86 \\
\hline Corporative culture & 4.01 & 1.03 & & \\
\hline Employer's reputation & 4.03 & 0.93 & & \\
\hline Flexible working hours & 3.64 & 1.22 & 3.46 & 1.22 \\
\hline Modern equipment and technology & 3.85 & 0.99 & & \\
\hline Private health insurance & 3.14 & 1.26 & & \\
\hline Use of business cars & 2.21 & 1.22 & & \\
\hline Permanent workplace & & & 4.05 & 1.05 \\
\hline Recognition of results & & & 4.07 & 0.93 \\
\hline Total & 3.77 & 1.02 & 4.06 & 0.98 \\
\hline
\end{tabular}

Source: Authors' work

Respondents were asked about reasons that would cause departing from their current working place. As the main reason the not satisfactory recognition of results was quoted, followed by low wages and poor human relations in the company. Impossibility to advance in job and not clear job division in working teams were also mentioned as factors, which influence workers' decisions.

\section{Discussion}

In the next phase of our investigations a comparative analysis was performed using the SPSS 20 statistical package. The Pearson Chi-square test was applied to find if there are statistically significant correlations between pairs of variables, namely: the level of education and gaining additional information on the employer; age of respondents and sources of information they use about jobs; level of education and parameters important when searching for new jobs; years of service and parameters important when staying with the current employer; and age of respondents and sources of information about the employers.

There is no statistically significant difference between respondents of different levels of education when deciding about acquiring information about a new employer. Also, all age groups use Google, Facebook, Linkedln, websites and opinion exchange websites as information sources with similar frequencies. Comparison of respondents distributed by age groups and frequencies of using websites for job ads it was found that younger persons highly statistically significantly more often use this source of information compared to the older group $\left(\chi^{2}=34.95, p<0.01\right)$. The same is the conclusion when comparing usage of employers' websites, namely younger respondents use this source more often than older $\left(\chi^{2}=24.00, p=0.02\right)$, besides that older use personal contacts more rare than younger $\left(\chi^{2}=37.63, p<0.01\right)$.

Information about current employer is gathered from different sources. The use of employers' websites, websites for job ads and personal contacts are more important for respondents of younger ages than for older (respectively $\chi^{2}=35.21, p<0.01$; 
$\left.\chi^{2}=31.58, \mathrm{p}<0.01 ; \chi^{2}=22.57, \mathrm{p}=0.03\right)$. Contrary, older age groups use data from and data from the National agency for registers compared to younger respondents $\left(\chi^{2}=24.07, p=0.02\right)$.

When searching for new jobs, different factors influence decisions to chose a specific workplace, and these factors are in some cases different for workers of various levels of education. Statistical analyses show that although they are very important in general, there are no significant differences between educational groups when issues like wages, job security, human relations, corporative culture, flexibility of working hours, use of modern equipment and technology and private health insurance are in question. The only statistically significant correlations were found for two elements. Higher educated workers require more possibilities of advancing to higher positions in their jobs compared to persons with less levels of education $\left(\chi^{2}=37.38, p<0.01\right)$. Despite the opportunity to use official cars in their job is not an important issue for workers in general, it is interesting that persons with lower levels of education prefer this possibility significantly stronger than others $\left(\chi^{2}=34.66, p<0.01\right)$.

\section{Conclusion}

Contemporary business conditions and market situation to a great extent differ from the situation experienced 10 or 20 or more years earlier. The development of technology, of the Internet and of the artificial intelligence was followed by advancement of new knowledge and professions, so lack of quality workforce is more explicit than earlier. Cited changes caused alterations in behaviour of both employers and employees on the labour market. Candidates who possess specific scare knowledge and skills and have substantial working experience are enabled to select between companies and to set conditions to employers. Those companies that want to hire these professionals have to undertake actions to attract the attention of the goal group of workers; this is closely connected to employer branding.

Employer branding is a process initiated inside the company through developing good relations between employers and employees and through maintaining good communication between them. Communication is a complex and delicate process; various factors have influence on it, so it very often becomes inefficient and inadequate. This has negative effects on working processes, results and company relations. Finally, workers will lose their motivations, and serious internal dissatisfaction will spread throughout the company. The sole external branding does not have desired effects in this situation, integrated internal and external branding is than needed to build company's image on labour market.

The results of our investigations show that in most cases candidates for jobs acquire additional information on employers. Every generation has its own information channels, which it uses and considers them to be credible. Employers have to meet the needs of candidates for information, or otherwise they will lose the opportunity to build proper relations with them even before their employment. If a company intends to employ a quality professional it has to identify and attract him. Companies that have active attitude towards information needs of their candidates have several advantages. These companies have to actively search for quality candidates, to apply appropriate strategy in accessing the candidates, to present business attitudes, working conditions, values and image of the employer, and finally through a short selection activity to employ the required quality candidate.

Investigations performed in this paper are connected to related topics like the automation of the selection process, acceleration of the selection process, make the selection of most quality candidates more efficient, effective management of the employment process (interview scheduling, interview carrying out, communication 
with the candidates, evaluation of candidates and offerings for employment), give sufficient information about the potentials of the company to the candidates, reducing costs of new employment, measuring productivity of new employees and acquisition of talents.

\section{References}

1. Anselmsson, J., Bondesson, N. V., Johansson, U. (2014), "Brand Image and Customers' Willingness to Pay a Price Premium for Food Brands", Journal of Product \& Brand Management, Vol. 23, No. 2, pp. 90-102.

2. Backhaus, K., Tikoo, S. (2004), "Conceptualizing and researching employer branding", Career Development International, Vol. 9, No. 5, pp. 501-517.

3. Ciric, Z., Stojic, D., Sedlak, O. (2015), "Multicriteria HR allocation based on hesitant fuzzy sets and possibilistic programming", Acta Polytechnica Hungarica, Vol. 12, No. 3, pp. 185-197.

4. Collins, C. J., Han, J. (2004), "Exploring applicant pool quantity and quality: the effects of early recruitment practices, corporate advertising, and firm reputation", Personnel Psychology, Vol. 57, No. 3, pp. 685-717.

5. Chunping, Y., Xi, L. (2011), "The Study on Employer Brand Strategy in Private Enterprises from the Perspective of Human Resource Management", Energy Procedia, Vol. 5, pp. 2087-2091.

6. Dell, D., Ainspan, N., Bodenberg, T., Troy, K., Hickey, J. (2001), "Engaging employees through your brand", The Conference Board of Canada.

7. Edwards, M. R. (2009), "An integrative review of employer branding and OB theory", Personnel Review, Vol. 39, No. 1, pp. 5-23.

8. Pejanović, R., Sedlak, O., Ćirić, Z., Grubić Nešić, L., Mitrović, S., Eremić Đođić, J. (2016), "Marketing Decision Making by Applying the Expert System", in the Proceedings of the ENTRENOVA ENTerprise Research InNOVAtion Conference, Zagreb, 280-286.

9. Sullivan, J. (2004), "Eight elements of a successful employment brand", ER Daily, Vol. 23, No. 2, pp. 501-517. 


\section{About the authors}

Aleksandra Marcikic Horvat was born in 1985 in Subotica, Serbia. She graduated from the Faculty of Economics Subotica at the University of Novi Sad in 2007 and obtained PhD in 2014 from the same institution. She currently holds the position of Assistant Professor at the Faculty of Economics Subotica, University of Novi Sad. Her main fields of interest are: operations research, multi-criteria decision making and business statistics. The author can be contacted at marcikic@ef.uns.ac.rs.

Radovan Pejanović is a full professor at the Faculty of Agriculture, Department of Agricultural Economics and Rural Sociology, University of Novi Sad. He obtained all titles from assistant to full professor. He teaches at the undergraduate, graduate and doctoral studies at Agricultural Economics studies and studies of Agro-tourism and Rural Development, courses: Microeconomics, Macroeconomics, Principles of Economics, Entrepreneurial Economics, Rural Economics, Methodology of Scientific Research, Organic Food Production Economics. He mentored numerous undergraduate, master and doctoral theses. He is a member of the Scientific Society of Economists of Serbia, president of the Scientific Society of Agricultural Economists of Balkan, member of Matica Srpska, member of Anthropological Society of Serbia. $\mathrm{He}$ is a full-time member of International Management Academy, as well as the Development Academy of the Serbian Agriculture. He was vice-dean for finance (two terms), vice-rector for finance (two terms) and rector of the University of Novi Sad. The author can be contacted at pejanovic@uns.ac.rs.

Zoran Ćirić is an associate professor at the University of Novi Sad, Faculty of Economics Subotica, working within the Department of Business Informatics and Quantitative Methods. He is involved in the realization of the teaching process on basic studies, master studies as well as on PhD studies in subjects close to his scientific interests: Management information systems, Project management, Business process, Knowledge management. The author can be contacted at ciricz@ef.uns.ac.rs.

Bojana Ćirić is an PhD student of the University of Novi Sad, Faculty of Economics in Subotica. The author can be contacted at bojana.ciric@gmail.com.

Otilija Sedlak is a full professor at the University of Novi Sad, Faculty of Economics Subotica, working within the Department of Business Informatics and Quantitative Methods. She is involved in the realization of the teaching process on basic studies, master studies as well as on PhD studies in subjects close to her scientific interests: Operational research, Financial and actuary mathematics, Mathematics for economists, Quantitative methods in economy and management, Risk management. She has worked as the vice dean of studies as well as ECTS coordinator. The author can be contacted at s00609967@gmail.com.

Leposava Grubić - Nešić is a full professor at the University of Novi Sad, Faculty of Technical Sciencies, working within the Department of Industrial Engineering and Engineering Management. She is a Chair of Production Systems, Organization and Management. She is involved in the realization of the teaching process on basic studies, master studies as well as on PhD studies in subjects close to his scientific interests: Leadership and change, Motivating Employees, Organizational Behavior, Work motivation, Industrial psychology, Human resources management, Human Resource Management in Knowledge Economy. The author can be contacted at nesic@ftn.uns.ac.rs. 